DOI: $10.2478 /$ rjp-2020-0008

\title{
HIDING SHAME - A CASE STUDY OF DEVELOPING AGENCY
}

\author{
Sami Kivikkokangas ${ }^{a l l}$, Mikael Leiman ${ }^{b}$, \\ Aarno Laitilac \& William B. Stiles ${ }^{d,}$
}

\begin{abstract}
The hiding aspect of shame makes the study of shame difficult. In this article we aim to show through Hanna's case study how shame manifests and develops during the course of one psychotherapy process. This will be done using Assimilation analysis (APES) and Dialogical Sequence Analysis (DSA) to show in detail one idiosyncratic developmental path through which the relationship toward the problematic shame experience changes and develops in psychotherapy. Results show how the manifestation of shame toward the problematic experience of being seen was present in the first moments of the first meeting, but also how during the sequence of sessions 7 - 9 Hanna's relationship toward shame evoked referent unveils and developed gradually through therapeutic work from assimilation stage 2 to reaching stage 5-6 at the end of the $9^{\text {th }}$ hour. This study shows how Hanna was able to reach a new kind of active agency toward the shame that, in the beginning, held the agency in her 'community of voices', and how this understanding of shame's developing and hiding nature can be of use in a clinically meaningful way.
\end{abstract}

Keywords: shame, secrets, agency, DSA, assimilation analysis.

\footnotetext{
11 a Department of Medicine, University of Helsinki, Helsinki, Finland; 'Department of Psychology, University of Eastern Finland, Joensuu, Finland; 'Department of Psychology, University of Jyväskylä, Jyväskylä, Finland, 'Department of Psychology, Miami University, Oxford, Ohio, USA; Appalachian State University, Boone, North Carolina, USA; Metanoia Institute, London, UK.

Corresponding author contact details: Sami Kivikkokangas, Oskelantie 5 C 23, 00320, Helsinki; email: sami.kivikkokangas@protonmail.com, phone+358406477130
}

Acknowledgements: This work was supported by the Finnish Cultural Foundation, Gyllenberg Foundation and The University of Helsinki Funds under the Grant of the first author. 


\section{Introduction}

Shame is familiar to us all, but it escapes easy definition (Tangney, 1997). It can't be seen directly, it is bypassed (Block-Lewis, 1971), or it becomes visible only indirectly through the anticipated response of the other (Bahtin, 1984, 1991). This hiding aspect of shame makes it difficult to recognize in clinical encounters and in empirical studies. In this study we show how shame can be observed in psychotherapy by tracing its development and transformations using two qualitative methods in the intensively studied case of Hanna (Kivikkokangas, 2017).

Classically, shame is regarded as a self-conscious feeling, which is easily evoked when we face shaming, contempt or ridicule in interaction with an external other or an internalized other. The rejecting answer of the other feels like a problematic emotion in self-experience, something that needs disposing of. One must also avoid exposing what privately evokes shame in a social field. The experiential core of shame builds upon unlovability, where dirtiness, faultiness and worthlessness constitute the main pains of self-experience (Wurmser, 1983). Shame is private, it needs to be kept hidden and that is why it is everywhere and nowhere (Hästbacka, 2013, personal communication).

In psychotherapy, shame can function as an obstacle to the development of self-observation in the presence of the other. The vulnerability inherent in shame can prevent the step to enter into a developmental relationship (Tähkä, R., 2000; Ikonen \& Reckhardt, 1994; Lewis, 1971). The act of trying to establish and seek connectedness to another might feel too dangerous or revealing if the history is built on disappointments in reciprocity. It takes courage to enter into a developmental relationship: how to be courageous enough to enter into a relationship in a way that actively seeks connectedness and reciprocity with the other, where the answer of the other is not under my control or omnipotence - but depends on the other's response. Instead of seeking for reciprocity it is easy to cling on to a sadomasochistic, e.g. selfridiculing, way of relating to others or retreat from relations altogether. At the same time the problematic nature of shame points to a conclusion: what has been integrated in relation to another as unmet needs to be brought back to the relational experience field in order to be met and understood in a new way. 
The hiding aspect of shame makes its 'showing' problematic. This is implied in the previous models on shame (Lewis, 1971; Wurmser, 1983; Ikonen \& Reckhardt, 1994; Siegel, 2015), where concealment as a response to feeling ashamed in front of other/s makes the investigation of the emotion word challenging. Shame is often indirectly expressed. When you can call shame a 'shame' (as a self-conscious feeling), it might be argued that it is no longer shame (in the way it has previously kept the person hidden from others and oneself). At its core is shame then a self-conscious feeling or, the exact opposite, an unconscious feeling? The availability of the entire data set enables the researcher to identify shameful experiences later in the therapy and then follow the development of the gradual unveiling of the nature of events from the beginning of the therapy. In this way we can see how shame is expressed indirectly or warded off in the beginning of the therapeutic process, where we don't know what the concealment is directed at, but how we can gain understanding about the nature of events about the shameful experience through therapeutic work.

\section{Assimilation of Shame}

The assimilation model conceptualizes the psychotherapy outcome as a change in relation to a particular problematic experience rather than as a change in the person as a whole (Stiles et al., 1990, 1991). In the assimilation model the patient's relationship towards the problematic experience goes through a sequence of developmental transitions in which the relation and awareness of the problematic experience can change from being warded off to being integrate into the total personality. This developmental process is described in the eight-stages of assimilation of problematic experiences sequence (APES), which are listed in the Method section.

At the beginning of therapy, the patient's problematic experience can match any assimilation level and any movement up the scale can be regarded as progress. Research on the APES has shown that successful assimilation of problematic experience does not proceed in a standard or linear way, particularly because clients frequently shift from one strand of a problem to another, and strands are assimilated at different rates (Caro Gabalda \& Stiles, 2013). 


\section{Research aim and design}

The aim of this case study was to investigate how shame manifests itself in the clinical hour. The research question was: How is the problematic experience of shame manifested in the patient's utterances, and how does the relationship toward the shame-evoking referent develop and change during psychotherapy?

To study shame experiences in the patient's utterances and their development across sessions, we used assimilation analysis (Stiles et al., 1992; Stiles \& Angus, 2001) and dialogical sequence analysis (DSA; Leiman, 1992, 2006, 2012) in combination. These two qualitative methods are described in later sections. Assimilation analysis was used to describe and conceptualize the development and change toward problematic experiences on the individual level. DSA, as a microanalytical method, was used to analyze self-observation and utterances. The combination of assimilation analysis and DSA has been used successfully in previous research (Tikkanen, 2015; Leiman \& Stiles, 2001). To our knowledge, this study is the first to use modern microanalytic methods to investigate shame in the clinical hour.

\section{Method}

\section{Patient, Therapist and Case Materials}

The patient, named Hanna, is a middle-aged woman, who sought psychotherapeutic help for binge eating and worsened psychic health due to traumatic life experiences. Her case forms an intensive case study that has been approached previously from the viewpoint of working through different emotions (Keto, 2010) and therapeutic interaction. Keto (2010) concluded that the therapy progressed through different phases, where only after sufficient working though of emotional numbness and guilt, it became possible to focus on feelings of shame. In addition, Keto (2010) pointed out a how it was typical that, after working on problematic issue, it was followed with a break from being talked about in therapy, only to be returned later on in therapy.

The therapist was an experienced integrative psychotherapist, where therapy was conducted on a weekly basis for a year. The case material was gathered in the Psychotherapy teaching and research center at University of 
Jyväskylä. It consists of 32 sessions that were videotaped, and transcripts made based on these videotapes.

Assimilation of Problematic Experiences Sequence (APES) and Assimilation Analysis

The APES (Stiles \& Angus, 2001; Stiles et al., 1991) summarizes psychotherapeutic changes in a patient's relation to a particular problematic experience in the following sequence of eight stages:

0 Warded off,

1 Unwanted thoughts/active avoidance,

2 Vague awareness/emergence,

3 Problem statement/clarification,

4 Insight/Understanding,

5 Application/Working through,

6 Resourcefulness/problem solution,

7 Integration/mastery.

The sequence is considered as a continuum, and intermediate stages (e.g., 1.4, 3.6) are possible. Researchers can use these stages as a way to describe their estimates of the degree to which the problematic experience has been assimilated. The APES has sometimes been used as a formal rating scale. However, we did not do formal APES ratings in this study, but instead used it as a way to be precise about our own interpretations of passages in the text.

Assimilation analysis (Stiles \& Angus, 2001) is a procedure for tracking the idiosyncratic developmental path of an individual client's change processes. It is a flexible procedure that generally follows the following four steps:

1 Familiarization. Recordings, transcripts, and other case material are intensively reviewed.

2 Theme identification. Based on the acquired familiarity and notes, the investigators identify themes or problems that seemed salient and therapeutically important. It is often easiest to identify a problem after it has been clearly formulated (APES stage 3) or when insight is achieved (APES stage 4; Leiman \& Stiles, 2001). Once the problem is clearly identified, it is often possible to recognize incomplete or distorted manifestations at lower APES stages in earlier sessions. 
3 Extraction of theme-related material. Session material relevant to the focal theme are excerpted and examined in sequence to highlight the changes or lack of changes.

4 Interpretation. Changes in the expression of the focal problem are described and interpreted in theoretical terms, such as by applying the APES.

\section{Dialogical Sequence analysis}

DSA is a microanalytical tool to study utterances (Leiman, 2006, 2012). The conceptual tools of DSA are used to denote and formulate internalized action patterns and reciprocal patterns mediated through utterances (Leiman, 2012; Tikkanen, 2015). The theoretical concepts of DSA are based on Bakhtin's theory of utterance (Bakhtin, 1981, 1984), Vygotsky's theory of sign-mediated activity (Vygotsky, 1978) and the basic concepts of cognitive analytic psychotherapy (Leiman, 1992).

The basic unit of analysis in DSA is the semantic position. Aligning with the activity theory all psychic activity, utterances are specific type of actions and are object directed. The relationship between subject and the object is reciprocal, and it determines the subject's relationship to the object. As a unit of analysis a semantic position can be summarised as the referent and the relationship to the referent. The semantic position corresponds with the analytic unit of the assimilation model, the subject's attitude to the object (Stiles et al., 1992). Both require that the object is spelled out in the analysis and assume that the subject has a specific relation to the object.

In this study, the following working definition of the unit of analysis and semantic position is used: shame is the emotion word that describes the subject's relationship to the referent. From a research perspective this is problematic, because if shame is indirectly expressed there might not be 'emotion word' to be seen from the utterance. The problematic shame experience shows itself through the avoidance of it.

The aim of analysis is to identify these recurring patterns of positioning with regard to a varying range of objects. Utterances are also actions and the objects of actions are called 'referents' in DSA. Utterances are a special type of action in the sense that it has simultaneously two referents - the object of action and the addressee. When speaking I am at the same time speaking about something and addressing my talking to someone, where the real or 90 
expected answer from the other organises my expression and the choice of referents (for example if I don't trust the other I might not speak clearly about what is bothering me but select other mildly bothering things to talk about instead). These affect the dynamics of the semantic position: who one speaks to affects what can be spoken about and vice versa. By defining the quality of semantic position we can articulate how the subject relates to the referent and the addressee of his/her utterance. In research, DSA is always conducted in data-session groups. (see Kivikkokangas \& Leiman, 2019; Tikkanen, 2015)

\section{The procedure}

(A) Following the DSA procedure, the very first session was analysed to form a baseline. The initial case formulation began by constructing a hypothesis of salient semantic positions in a data session of the first episode.

(B) Following the assimilation analysis procedure, the first author read the transcripts from the whole therapy and watched from a video the relevant sequences used in this study. This was done to create a general understanding of the whole of therapy and how shame might manifest during the sequence of sessions.

(C) The problematic shame experience was defined using episodes in which it was clearly formulated. For this, we relied in part on earlier research on the Hanna case (Hartikainen, 2013; Keto, 2010), in which sessions 7-9 were shown to manifest ruptures in the therapeutic relationship associated with shame (Hartikainen, 2013).

(D) Episodes during sessions 7-9 that manifested shame experiences were selected for intensive analysis. This process was iterative in the sense that new episodes began to appear relevant and were included as the analysis proceeded.

(E) We described how shame manifested in the sessions 7-9 and how Hanna's relationship toward the problematic shame experience developed from APES stage 1 to ultimately reaching APES stage 5-6.

(F) The completion of the analysis of sessions 7 -9 enabled a return to the data from lower assimilation stages in earlier sessions with this enriched understanding of the problematic experience and its manifestations (Leiman \& Stiles, 2001) 


\section{Results}

The start of therapy: being seen as the problematic experience

The first clue of Hanna's problematic experience and her relation to it could be seen during the very first moments of the initial meeting, as Hanna completed a form related to the study. The therapy was conducted and transcribed in Finnish; selected excerpts have been translated into English for this paper by the first author.

Vignette 1 (session 1, lines 31 - 40, APES 1-2)

31 Hanna: For me it has always been a place of horror to be photographed or filmed, but here it is not noticed () that it can be forgotten () but I don't in the first place if I () or so or stiffen like a

32 THERAPIST: [mm] [mm]

33 HANNA: log although if () but I can prevent myself from thinking about it because it doesn't show in this room

34 THERAPIST: yes

35 HANNA: here is my () the date is () [I can't remember

36 THERAPIST: [today is the 28th]

37 THERAPIST: but its the kind of thing that one probably gets used to that it is then not () remember that ()

38 HANNA: when you don't have to see it by yourself

39 THERAPIST: yes

40 HANNA: that's the way it goes () yes

In the first moments of the initial meeting before the formal beginning of therapy Hanna expressed her problematic experience: 'for me it has always been a place of horror to be photographed' (Vignette 1, line 31). This vividly conveyed what being seen felt like to Hanna. She continued by explaining how she coped with being seen: 'but here you don't notice it () that you can forget about it () but I don't in the first place if I () or if I or stiffen like a $\log ^{\prime}$ (Vignette 1, lines 31-32). It was not possible to tell from this early utterance how this semantic position toward being seen, her ' 'horror place' had developed or to understand the referential network this was linked to for Hanna. The semantic position showed a problematic relationship to a referent, the horror of being filmed, and her way of trying to shelter herself 
from her horror: 'I can prevent myself from about it because it doesn't show in this room. '(Vignette 1, line 34) The 'it' referred to the camera behind oneway mirror directed at her, but that she could not see. At this point, Hanna's problematic experience was apparently at APES stage 1, as Hanna actively avoided and preferred to not think about it.

Initially, the integrative psychotherapist overlooked these clues and didn't follow where these associations might have led to. The words that Hanna used to describe her experience of being filmed, 'I stiffen like a log,' expressed a feeling of paralysis, a lack of movement. The therapist's comforting formulations aimed at easing the emotional situation of the patient 'but it's the kind of thing that one here probably will get used to that one doesn't than () remember that' (Vignette 1, line 37) seemed aimed at bypassing the problematic experience. Hanna responded to sweeping away the possible problematic nature of being filmed at by saying 'like when one doesn't need to see them' (Vignette 1, line 38). This was affirmed by the therapist by 'so (it is)' (Vignette 1, line 39).

Hanna returned to the problematic nature of being seen a few minutes later:

Vignette 2 (session 1, lines 84 - 96, APES 3)

84 HANNA: a well () especially for me it's so hard to express any feelings that go on in my mind that they just don't ()

85 they don't show although of course they exist I don't get angry then if it was the time to raise

86 one's voice or confront something uhm () well I've not been crying a lot but just

87 that kind of () and like the kind of joyfulness that's gone I can't like for example anymore

88 laugh at all or the want is lost () but somehow I can't (example removed lines 89-91)

92 THERAPIST: $\mathrm{mm}$

93 HANNA: and if I'm anger of course sometimes the kind of feeling that one should say something about then I just feel like

94 the kind big pressure inside that tries to pursuit out it's the kind of anxious feeling I don't

95 know if it's like fear mainly or () or kind of anxiety that I don't say anything I 96 just smile and be like yes everything is very good 
Hanna's central problem of being seen was here manifested in social situations: 'it's hard for me to express any feelings that go on in my mind that they don't they just () they just don't show although they of course exist' (Vignette 2, line 84). The intonations, tones and gestures that accompany our utterances show, what kind of emotional relationship Hanna has toward what she is talking about (the referential object) position her reciprocally towards what is spoken about (the referential object). On the manifest level the reportlike way of telling, the abundance and monotonic tone is something that easily escapes from attention, something Hartikainen (2013) has also paid attention earlier in Hanna's way of talking. Hanna talks about the difficulty of expressing herself, and the way she speaks of it contains the same distancing shelter. When we speak using the tones that we use it tells us how we feel about something: report-like way of describing prevents those tones from evolving and thus hides the speaker's relationship toward the referential objects. Hanna poignantly described how her relationship toward her problematic experience was caught in the dialectical tension between being seen/exposed and not showing/being exposed: 'they just don't show although they of course exist' (Vignette 2, lines 84-85). Hanna hid herself by leaving her own attitude and feelings toward referential objects unexposed; this felt for her as 'pressure'. Not showing her relationship toward referential objects here was exactly her relationship toward the problematic referential object.

Hanna linked her difficulties in expressing emotions with her inhibitions in expressing aggression. This is an example of how the stage of assimilation is connected to the referential object. While talking about the invisibility of her feeling, Hanna seems to refer to the problematic nature of her actions 'and well () especially for me it's like really hard to express any emotions that go on in my mind that they don't () don't show although they of course exist' (Vignette 2, lines 84-85). This seems to indicate the problem moving between APES stages 2 and 3. Although Hanna didn't disclose to what referential object her hiding of feelings referred to (APES 4), she described her actions in a reflective way (Vignette 2, lines 94-96); that is, her description involved self-observation concerning the relationship between her emotions and actions: 'the kind big pressure inside that tries to pursuit out, it's the kind of anxious feeling. I don't know if it's like fear mainly or () or kind of anxiety that I don't say anything. I just smile and be like yes everything is very good. 94 
In summary, these vignettes from the first meeting suggest the following formulation of Hanna's problematic experience: Being seen and being exposed in front of another was very threatening for Hanna, leading her to lose her sense of aliveness and experience a sort of paralysis ('stiffen like a log'). She avoided this threatening relational positioning by denying or forgetting how she would be visible in the eyes of the other. Hanna had difficulty trusting others or accepting reciprocity, as was shown by her difficulty in expressing her own opinions or showing how she felt. As she put it, 'It's hard for me to express any feelings; they don't show although they of course exist'. For Hanna, the difficulty of expressing her opinion was related to her problematic relationship toward aggression; she felt that she avoided conflict in interaction in maladaptive way, not standing up for herself in situations where actions were needed to maintain her boundaries and dignity. Other people in general seemed frightening and anxiety provoking to Hanna, whose main way of dealing with these problematic situations (how to be in contact with another, how to keep one's own boundaries) was to be silent or try to please the other, and in that way maintain the connection to the other and avoid conflict by being submissive.

The story of Hanna's shame - sessions 7-9

In the next section, using the sessions 7-9, we will show how Hanna's shame was manifested in psychotherapy and how her relationship toward the shame-evoking referent was successfully transformed. We have divided Hanna's shame story into three sections: 'The horror of being exposed' (session 7), 'Going to middle school' (session 8) and 'Hanna's shame becomes visible’ (session 9).

The horror of being exposed (session 7)

The general theme of the session 7 was Hanna's horror of being exposed. The referential object of her horror was her father's behavior. Hanna began the session by talking about a couple who had visited their home the previous autumn. The man had been part of Hanna's father's drinking gang. Hanna's usual strategy of avoidance (APES 1) failed her here, and she revealed that her father had sexually abused her when she was a young girl (Vignette 3). The actions of the other (her father's drinking companion) addressed Hanna's 
problematic experience at APES stage 1 and the painful material emerged (APES 2).

Vignette 3 (session 7, lines 102 - 112, APES 2)

102: HANNA: I was furious at Denis just about like yes how great it is that () you know what this great man of yours (Hanna's father and the reference to sexual abuse)

103 did to me when I was well () the kind of young girl () and I didn't say like anything else

104 he () he just went () well went quiet () and that was it () or like () didn't know anymore

105 even that () what what he would say then it stopped the whole thing () there and () then of course when I had ()

106 said it then it was like totally terrible that now I have said it like that (and then) 107 THERAPIST: (how was it so) terrible/

108 HANNA: well that's the kind of thing one doesn't go out and say out loud first of all () one needs to be awfully precise () there are are things

109 from which one should () better be quiet about () to think at least to whom one says and to whom not () not the kind of ()

110 man who is like the ultimate Ogossipwatch () or like and then it was so terrible thing

111 overall that I said out loud or put into words that () that bad thing that () it shouldn't be like ()

112 one should be silent about it () and

Hanna began by speaking about the episode in first person ('I was furious'), but after the therapist's question, her answer was in the voice of the generalized other - speaking in a passive form, setting the prohibition (lines 108-109), and simultaneously distancing herself. This instantly led to anxiety about the ill will of the villagers, when the secret about the sexual abuse was revealed. However, Hanna did not understand the source her anxiety. That is, Hanna was not consciously aware of the referential object to which the anxiety referred to, although she felt the anxiety, and her position became visible in her reaction. 
Vignette 4 (session 7, lines 137 - 151, APES 1-2)

137 HANNA: if Denis (fathers friend) went to talk to somebody, if he told () in the villages where he moves around,

138 where everyone knew dad () and, like, would tell () what I have said, it would

139 only turn against me, (and like)

140 THERAPIST: (like how) do you think?

141 HANNA: Uhm, like that () hmm () that in the end it's me who is like the real cunt,

142 that I dear to derogate my dad's reputation. Dad has rested in grave for five years already ()

143 and I begin to speak about such matters () Uhm () suddenly that () it went () it would be () my evil deed () hmm I know well what kind of folks there live indeed.

The salient referential objects are 'father's friend' and 'village people'. Hanna describes, using quite laden expressions, their position to her, if she disclosed her father's behavior toward family members. It is noticeable that the composition is self-referential. Hanna perceives herself through others' eyes: 'It's me who is like the real cunt' and 'my evil deed'. The broader, social network of meanings behind such expressions involve father being an idealized war hero in the village. Interventions made by the therapist to encourage reflection remained unfruitful (Vignette 4, line 139; 144; 147), as Hanna described her way to escape the overwhelming anxiety - staying away.

Vignette 5 (session 7, lines 198-211, APES 1)

198 THERAPIST: [are you in contact] with them (removed lines 199-203)

204 HANNA: well not really that much () in that way that () that I don't for example like visit

205 anyone in that way or they don't visit us but these people that you bump into 0

206 always, these old persons of the village

207 THERAPIST: then it is in a way

208 also something like the sense that () hmm () that you can't for sure know that they would now say to you 
209 like that but you in a sense imagine that they think like that 210 HANNA: mm () in some way by knowing the nature of the kind of small countryside village ()

\section{'Going to middle school' (session 8)}

In session 8 Hanna's horror of being seen occurred within the therapeutic interaction. This proceeded in three stages. First Hanna described (Vignette 6 and vignette 7) how the understanding meeting with her cousin transformed her relationship toward the shame-evoking referent and enabled her to go to middle school. (APES 2-3) Secondly, while talking about the cousin, Hanna's bodily state shifted noticeably. The therapist pointed to this, but Hanna wasn't able to use the intervention and avoided the topic. (Vignette 8, APES 1-2) The horror of being seen emerged in the here and now interaction, which led to the third stage: Hanna later linked the 'mockery of the villagers' to the 'snort of the therapist' (Vignette, 10, APES 2).

In session 7 Hanna had related in an almost paranoid way to the villagers but couldn't consciously grasp what (referential object) this was linked to (APES 2). In session 8, she described how that problematic experience became clarified in a discussion with the therapist about a childhood talk with her cousin about going to middle school. Hanna's formulation 'I was so afraid that when dad gets drunk at the church village that I have to bump into him so' approaches an APES stage 3 formulation, but still left the feeling of shame unarticulated. (APES 2.5)

Vignette 6 (session 8, lines 244-253, APES 2-3)

244 HANNA: I well ()

245 I refused to go to middle school or the like from my fourth grade you should have applied

246 there but I was like totally that I won't go there and () well no one like understood

247 at all about it like what the kid is being difficult what has she gotten in her head an ()

248 needs to be hard-headed () and well no one got the idea that except my cousin

249 then who in the end got me to go to school just like in the way that he talked 98 
250 with me and () because he understood () to ask the right question in a way that um ()

251 is it about some people who are at the church village () where the school is and I said like

252 yeah () and that it is about it and () like I was so afraid about that my father drinks there at the village

253 that I have to bump into him that I () am not going to that school

Hanna described how she tried to solve the threat of shame that was linked to her father's behavior by refusing to go to middle school (Vignette 6, APES 2-3). However, she didn't have a reflective stance to her narration (APES 4). In the previous sessions Hanna related in a suspicious way to the villagers, but couldn't reach where that strong relating referred to (APES 2). Here (Vignette 6, lines 252 - 253) that problematic experience is clarified in the discussion with the cousin about going to middle school. Hanna's formulation (Vignette 6, lines 252) about fearing to run into the drunk father in the village approaches an APES stage 3 formulation but doesn't explicitly articulate the feeling of shame relating to this referential object (APES, 2,5). However, after the encouragement from the cousin, it became possible for Hanna to recognize her wish to go to school behind her fear (Vignette 7, APES 2)

Vignette 7 (session 8, lines 254 - 259, APES 2)

254 HANNA: well my cousin just said then that () not even mentioning my father or any names or like that but

255 there was just this kind of shared understanding created that () yes that you don't () need to like care

256 about that there is () like all kinds of stupid people who can say something nasty and () that

257 way but it's not like your fault you don't need to care about all that ()

258 just go to the school and well then I just wanted to go to school () so that it was so () or like

258 simple () in a way that () if someone had just talked about all the kinds of things that this 0 well

259 cousin for example underst- understood me and it 
The cousin's encouragement problematized the way Hanna had previously (Vignette 7) tried to solve in avoiding manner the threat of revelation of the shame of her dad's behavior by pointing to a solution 'if someone just had talked (to me)' (Vignette 7, line 258). The problematic experience was thus at APES stage 2, but it expressed an alternative position toward her shame in a not yet consciously grasped way. This anticipated the insights of the session 9.

While she was telling the story of the cousin, Hanna's bodily state changed noticeably. Therapist picked this up and referred to it as 'being moved'. This comment about 'being moved' by the meeting with her understanding cousin invites instantly the voice of the internal other to the scene, which invalidates everything. Hanna was not able to express her own experience freely. She didn't articulate or didn't know to what the relation term 'being moved' referred to. This is shown indirectly in her expression '(it felt) good' by saying something that functioned in the discussion as a way of ending the exploratory movement and aligning to something that the therapist has said how it should have felt.

Vignette 8 (session 8, lines 277 - 287, APES 2)

277: THERAPIST: I just felt a moment ago that it was somehow like that you had been moved when you

278 you told about it but () did you have the kind of feeling

279 HANNA: well maybe what could be the cause then is the cousin was very moving or like he was like

280 in my childhood the kind of () that it's moving because he was so () um () good

281 THERAPIST: I think that what it felt for the little girl always felt good when somebody talked and somebody who

282 cared and () that you can get some kind of a () or does it produce the kind of connection

283 to the feelings of the little girl () these experiences where you re () that you were cared for and ()

284 that somebody understood () sometimes

285 HANNA: well yes, that again in that way () hard I'm trying to think I don't () I don't find the () thought 
286 that way () yes the connection

287 THERAPIST: that you didn't have the kind offeeling then but I interpreted a bit wrongly it seems

In Vignette 8, Hanna identified with her experience of being worthless. As she put it, 'I try hard to think I don't () I don't find it ()' (Vignette 8, lines 285 - 286). In her sentences she used the first person without a reflective stance to what she talked about, and describing without a reflective stance signals APES stage 3. In the therapeutic relationship, this was followed by Hanna's projective attitude towards a therapist's 'snort', which she understood as mocking and judging her (Vignette 10. Hanna was able express the content of this projected attitude toward the 'snort/laughter' but was not able to relate to it reflectively (APES 2). We understood this as a repetition of Hanna's attitude to the mocking villagers, where the threat of mockery and scorn evoked the same way of acting toward the projectively described experience. Hanna controlled the discussion by quickly going forward from this, not able to reflectively stop to explore the 'snort' and what kind of referential network it might be connected to. However, the therapist's intervention of inviting Hanna to reflect on this the problematical relational situation succeeded, and she then addressed this issue.

Vignette 10 (session 8, lines 423-431, APES 2-3)

423 HANNA: you laughed or it could be seen from the face that you let out the kind of noise that mainly sounded like laughter (Here Hanna refers to the therapist's snort that occurred before this comment) 424 that I didn't say this thing correctly // I thought //

425 that I need to change this word order or do something to this sentence 426 in that situation you would have thought like that oh god again that Hanna turns this around

427 against herself //

428 because you had just said before that here I am now

429 blaming myself and that sound just like that //

430 isn't that person capable at all //

431 of ceasing to blame oneself 
Hanna first described 'the snort' (Vignette 10, lines 423-424) unconditionally ('you laughed'), then as if correcting herself about the interpretation of the facial expression ('or it could be seen even from the face'), and in the end as if it was her tentative interpretation of the therapist's expression ('or you revealed the kind of noise that mainly sounded like laughing'). This is a crucial moment of change, where Hanna takes initiative in her own hands in order to deal with the experienced problematic situation instead of being silent and ashamed, or silenced by the shame. Although Hanna can take the initiative and describe how the threat of being laughed affected her expression ('I thought, I need to change this word order or do something to this sentence'), she's unable to gain reflective stance toward her projective attitude '(Vignette 10, lines 447-453) regarding what the therapist 'really' thought about her. The therapist pointed out that it might sometimes be useful to say that she doesn't understand and not be silent just to please the therapist. To this Hanna - repeating the problematic situation just described - responded without actually grasping the idea in the therapist's formulation (APES 2; Vignette 11).

Vignette 11 (session 8, lines, 531-536, APES 2)

531 HANNA: this is again in that way hard like how should it be continued from here like ()

532 that now I need to be careful and () say () if I notice that I'm beginning to be

533 THERAPIST: did it go difficult

534 A. to be pleasing or () just tell you that I don't understand you () or like this but how I'm going to like

535 be pleasing to you from this moment on but I'm telling you now that I have the kind of intention () and

536 that can be stopped then there

This momentarily rupture in therapeutic relationship was addressed and worked on, leading to a bad memory from Hanna's previous therapy where she felt laughed at and mocked. Although we don't know what 'really happened', as she described it, that rupture remained hidden from the joint observation and work. The previous therapists' laughing had evoked 'shame.' This sort of thing 102 
had happened before, and Hanna was trying to avoid it happening again in this therapy. However, Hanna hadn't been able to build a reflective stance toward threat of shame. When events made her feel worthless, she either tried to avoid the shame or was driven to projective ways of relating to the other (APES 2).

Vignette 12 (session 8, lines 544- 552, APES 2)

544 HANNA: He like laughed at that kind of spot that don't

545 for god's sake laugh like that () and in that spot () that somehow started, me being more

546 being careful after it, that was () unpleasant experience. I thought that in no circumstance

547 I would want to repeat that here with you () // or that

548 I would say something like that the therapist couldn't stand it () //

549 or you to be angry at me, it (the last therapists actions) was terribly

550 shocking I didn't expect that it would have happened like that and from it one became

551 a bit scared or that one tries you know even more now when one is in therapy that there wouldn't be created

552 that kind of () situation

\section{'Hanna's shame becomes visible' (Session 9)}

In session 9 Hanna was able to form a new active relationship towards to the shame-evoking referent. She was able to integrate it in a way that generated a new understanding to her own life history. Changes in assimilation stages take place in three stages: 1.) reaching a new understanding of her problematic experience (APES 4; Vignettes 13-14), 2.), working through this new understanding (APES 5; Vignettes 15-16), which eventually led to 3.), a partial solution of the problematic shame experience (APES 6; Vignettes 17-18).

In the beginning of the session 9 Hanna returned to the feeling of 'being moved' by the meeting with her cousin. Apparently, she had thought about this on her own between sessions. She spoke in first person yet did not identify with the feeling of being worthless (Vignette 13, lines 15-16). The difficult feeling, which Hanna couldn't understand, demanded to be thought about (Vignette 13, lines 15-16). This was an interesting illustration of how a 
warded-off problematic experience (Vignette 13, line 11, APES 0), signaled by a difficult feeling, can become a topic of self-observation. The relationship to the referent acts as if it is a clue to the referential object, which is not yet articulated clearly. (Vignette 13, lines 12-13, APES 2-3)

Vignette 13 (session 9, lines 11-16, APES 2-3)

11 HANNA: There when we talked about my cousin who made me to go to school () well eh and about

12 speaking about it suddenly in some way () it wasn't instantly at all pleasant, but it was really totally

13 terrible () it was really unpleasant, like some kind of ugly black troll 14 THERAPIST: really

15 HANNA: somewhere there at the edge, I didn't know, like what it is () and from it I just thought

16 like two days that why did I got the feeling like that (and well)

At first it was difficult for Hanna to grasp what the 'terrible feeling' referred to. First, she linked it to the disappointment that the cousin hadn't asked about previous bullying experiences and had just said to go to school. Then, Hanna responded to the therapist's clarifying question focusing on the feeling the cousin evoked: 'but behind it there was like the kind of () like anxiety () or like sma small horror.' (The small horror referring here to Hanna's hesitations uttering the word 'sma small') Hanna was then able to grasp something (APES 3-4) that she hadn't been in touch with in the previous session.

Vignette 14 (session 9, lines 73-76, 91-93, 96-97, APES 3-4)

73 HANNA: the conversation wasn't nice at all and I remember that I was sullen a lot and I was very

74 monosyllabic but then afterwards really relieved and then I got to 75 school //

91 I would have stuck to what I wanted after saying many times that I am not leaving, but //

92 he somehow like understood my secret this cousin //

96 somehow like I was so pissed at 11 years old that I was like revealed and that he like reads me like an 
97 open book I don't remember () but something made me be very sullen at that phase when we talked

Then Hanna gave examples to explain the referential network to which the shame evoking-memories were linked. She also explained how she had tried to survive with them, for example, when her father came drunk to her school bus or when 'the teacher made my dad the eye eyesore like the whole class ran () to the window to stare.' Hanna described her feelings in this instance:

Vignette 15 (session 9, lines 163-172, 220- 238, APES 4-5)

163 HANNA: I was like indignant about it and //

164 and I somehow just thought that I am not going there () //

165 and I just stayed () sitting there and the teacher () talked there

166 more like where she has seen the man before and the like () and at that time it was beginning to be () terribly () clear that it is my father () I became terribly () small and

168 puny it was like so self-evident thing that I couldn't stir a bit from my seat that I like

169 now () I'm like disappearing to nothing hopefully () and well () no one said a thing

170 like knowing the man or the like but then one boy came who was from my neighborhood () to me and //

172 laughed so much and said it's your father //

220: HANNA: had to go somehow, had to be not thinking //

223 to raise and arrange a kind of posture to one's face that is thought to be appropriate

224 uninvolved calm willingly like without a- any expression and it is about that one looks to no direction //

226 just to place one to sitting and starting to look at the bench //

228 I don't know what others thought but for me it was terribly

229 shameful. I needed to develop a kind of shell somehow to keep face

Hanna's way of trying to deal with her shame was similar to her strategy in 'going to middle school': being silent and avoiding the referent that evoked 
shame ('I refuse to go'). By working between the sessions on her own, she gained a new understanding of the history of her shame experience and how her ways of dealing with it had formed. The relation to her father's behavior (the referential object) wouldn't inevitably have had to develop into shame ( 'one could have also raised in another manner to relate to this'; Vignette 16, lines 300-302). Being exposed or becoming visible was the central threat to be avoided (Vignette 16, line 302). Here Hanna began to achieve a sense of agency; which is shown in her active and forward-looking stance toward her problematic experiences (Vignettes $16-19$ ).

Vignette 16 (session 9 lines 291-302, APES 5)

291 HANNA: that it was mom who so terribly communicated to me that 292 really could raise up in some other way of relating to the thing // 293 so this is for us such a terrible shame, shame that your father is like that and () and () all () what then could dad now 297 do, mom painted all kinds of pictures that () If dad does this and that if happens 298 that kind and this kind then () we are plunged into feeling ashamed of him. That frightens so much that () or ()

299 like sure it catches quick. I was probably well for example when I started 300 school then I was steeped in to the kind of () shame and fear that I was the kind of terrible thing

301 on you like how to keep this () hidden and avoid and () lie and do whatever in such way that this terrible shame wouldn't be revealed

Working on the different sides of the problematic experience continued, when the therapist returned to the 'therapists snort' and the threat of shame in the relational context with a significant other. Afterwards it was possible for Hanna to describe and reflect upon the situation in a less projective way, which had not been possible in the previous session (Vignettes $9-11$ ). Hanna described how she didn't feel the 'snort' in that situation had been unkind or mocking laughter in the sense she had felt the previous therapist's behavior. Hanna talks about her experience from another stance than in the previous session, where during the problematic experience her attitude to the therapist was projective without reflection ('You laughed!', Vignette 9). Here (Vignette 16) Hanna places the not-understanding and mockery to the 106 
previous therapist. In short, Hanna denies having felt the current therapists snort as potential mockery - although the data shows, that she did (Vignette 9) - and in this way protects the image of the present therapist (from this kind of behavior that the previous therapist was capable of).

Vignette 17 (session 9, lines APES 5)

338 HANNA: shame that was what came out of it () I'm stupid () I am such a 339 stupid strenuous and unbearable goose that even a therapist can't stand me, now he got already

340 angry //

358 even he of course didn't probably think like in that fashion but //

360 but I take it out on myself because I am

362 the kind of person I am, and of course I got that (the way of thinking of herself as 'stupid strenuous and unbearable goose') from shame

Hanna next revealed aspects of her mother that had previously been unspoken. Indirectly Hanna problematized the way she had developed. She seemed to be working toward an understanding of her shame, where the shame about her dad's behavior hid something more. Hanna couldn't talk to her mother because she feared or expected her mother's anger or mockery (Vignette 18, lines 484 - 485). Hanna described her fear of becoming like her mother, concerned with how she might prevent this.

Vignette 18 (session 9, lines 482-490, APES 5)

282: HANNA: usually they say that daughters tend to become like their mother or one notices in oneself

483 something like that but I don't notice like anything good () but that I would not be becoming like

484 the kind of who () bursts explosively suddenly get angry over something () or that is like so

485 cold like mom knew how to be the kind of ice cellar () where she threw mockery sticks () //

486 what if I don't notice that I change //

487 I don't know why mom was a bitter human she was () tired and 488 sick and bitter () if the same happens to me () here one must 489 somehow put on a fight on if it could somehow be prevented and I don't know () 
Hanna's self-observations about the previous session (session 8) thus led to a new self-understanding. This enabled her to move from the 'dark cloud, mirthless and stuck' toward a more 'liberated, alive and talking with others kind of being and doing.'

Vignette 19 (session 9, lines 512-520, APES 5-6)

512 HANNA: I can do the kind of very small things that have been to me like 513 impossible because I've been afraid of so much () what consequences are there if one

514 goes and does something //

515 I feel myself at least a bit more courageous () that I dare to say about the kind of things that I previously wouldn't in anyway () open my mouth and 516 then try it a bit how it () feels like to dare () really () to speak where one speaks and

517 then to notice that it wasn't so

518 bad that I can do it and () I did it anyway () that there came now shame 519 or well () embarrassment () no one (no) said that stupid, well when I have noticed that there's actually no () one saying things like that

520 then I am going to () continue it (the daring to say the kind of things she wouldn't previously say) and try more things that come with that (way of being active)

In summary, during session 9, Hanna first described how her developed self-understanding of her 'terrible feeling' was linked to her meeting with an understanding cousin (Vignette 13). Here Hanna's assimilation of the shame evoking problematic experience moved from APES stage 2 to 3 (Vignette 13: Hanna didn't want to go to school but was not aware of how her 'terrible feeling' was linked to the meeting with the understanding cousin). The work proceeded towards assimilation stage 4 insight (Vignette 14: Hanna came to understand that the terrible feeling was linked to the revealing of the object of her shame to the cousin, triggered specifically by his understanding of why and what Hanna avoided by not going to school). Enabled by this understanding, Hanna next clarified her understanding of how the behavior of her dad had developed into what she called 'shame'.

Next, Hanna gradually broke the silence around her story of shame. Through therapeutic work Hanna addressed the previously unspoken role of 108 
her mother in generating her shame (Vignette 16-18; APES stages 4 to 5). At the end of session 9 Hanna described the change she felt herself about the problematic experience (Vignette 19): the shame had - at least partially - been integrated into her self-experience, accompanied by a new sense of agency and even laughter in daily life (APES 5-6).

\section{Discussion}

Our broad aim was to show how shame manifests and changes in psychotherapy. This was done using APES and DSA in Hanna's intensively studied single case. The more specific research task was to show how the problematic shame experience manifested in the patient's utterances, and how Hanna's relationship toward a shame-evoking referent developed and changed during her one-year therapy process.

Shame was central in Hanna's very first words, but only later was it worked on jointly, and only through this did it become understandable and meaningful. Across the sequence of sessions 7-9 Hanna's problematic experience of shame emerged: first as a clue or hint, and then gradually assimilated, following a nonlinear trajectory from APES stage 1 to APES stage 6. For Hanna, this meant a new kind of developing agency toward the shame that in the beginning held the agency toward her, in her 'community of voices' (Stiles, 1999).

Hanna revealed the problematic nature of being seen or exposed in the first minutes of the first meeting. She spoke casually of being filmed as 'place of horror' for her while she was filling out the informed consent form. The therapist did not pick up on this comment. This expression, which could not have been understandable to the clinician at the time, loomed large to the researchers after they had assessed clinical data from the whole period of the therapy.

For several sessions Hanna said nothing about shame besides her casual comment revealing her horror of being seen. The relationship between being seen and the gaze of the other (camera) is reciprocal. This semantic position (horror of being seen) subsequently appeared in relation to a variety of referential objects, including when Hanna revealed the secret about the sexual abuse perpetrated by her dad's drinking buddy Denis (Vignette 3), or when Hanna referred to the impossibility of going to middle school (Vignette 
6-7), or when the cousin understood the secret about the true referent of Hanna's shame (Vignette 13-14), or in the narration about the dad who came drunk to her school bus (Vignette 15). Through therapeutic clarification of the referential network it became possible to understand how all of these concerned her shame.

During sessions 7-9 Hanna's relationship toward the shame evoking referent(s) changed and developed. At the beginning of session 7, she described how her impulsively revealing the secret of her sexual abuse evoked a terrified, paranoiac attitude toward others (APES 2). In session 8, she described how her meeting with the understanding cousin clarified how her father's behavior was the referent of Hanna's shame (APES 3). Then the fear of being ashamed became experientially felt in relation to the therapist's snort/laughter, where Hanna took the initiative to speak about it. In session 9, after working through this problematic experience in the therapeutic relationship, Hanna was able to assimilate a new kind of understanding of the 'terrible feeling' linked to meeting with the cousin (APES 4). Subsequently, Hanna was able to work through and integrate her shame experience as part of herself. She then felt at more liberty to express herself. Working through the new understanding contributed a new perspective on her relationship toward her father's behavior, which could have developed in some other direction than shame. Hanna also noticed how she was identified with her mother's shame about Hanna's father, doubling the intensity of her shame in this way.

\section{The possibility of initiative turning from pre-narrative shame experience to dialogue with a significant other}

From a clinical point of view four central steps can be identified from Hanna's process that enabled the new kind of active agency toward her problematic shame experience:

1) A relationship to a significant other, who does not shame, ridicule or mock. This is aptly condensed in the way Hanna described the most meaningful moment in her therapy in an interview conducted after the end of therapy. In the fourth session Hanna had simply casually mentioned a book she had been reading. The therapist asked what book it was, and she answered that it was one by Alice Miller called 'The tragedy of the gifted child'. The therapist said she knew the book and asked what was meaningful about it to Hanna. This was the moment 
Hanna herself identified as the most meaningful change event in her therapy. The interviewer asked why this was so, and Hanna's response is revealing: 'When I told her about it, the therapist didn't laugh or mock me but was interested and asked me what the book was and what it was about. There and then, I remember, I thought to myself that this is a person I can trust and rely on. And then I was able to let go in therapy and talked about all'. It seemed to us that, in Hanna's mind, she became able to trust in the experience of being held in the therapist mind and seen by her in accepting way, which enabled her to decide in those early stages to 'let go, trust in therapy and talk about it all'. The availability of the experience of a helpful other seems to be crucial for change, where the emergence of such availability seems to go hand in hand with the evolving self-agency (see Kivikkokangas, Enckell \& Leiman, submitted).

2) In addition to her shame experience being met in a new way in a nonshaming relationship to a significant other, Hanna's problematic shame experience settled also in a new way in her inner dialogue. This can be seen in Hanna's typical way of continuing the therapeutic process on her own between sessions (see also Hartikainen, 2013), where she didn't return to her symptom filled reality of binge eating and anxiety. The problematic shame experience had entered into dialogue as something that can be thought about and used to begin the narration of a non-narrated-story. This is an important addition to the psychology of shame: shame is shame as long as it can't be verbalized, it can't be talked about or be narrated. The verbalization from the beginning of the therapy about the 'horror of being seen in front of another' is the first step toward reflection. As was shown, this proceeded through the narration of the meeting with the understanding cousin toward the verbalization of the hidden reason behind her shame (dad's behavior), where Hanna gains a new kind of awareness toward her resistance and the shame linked to the disclosure of this secret to others.

3) A crucial moment of change, or evidence of the change that has already taken place ${ }^{12}$, is how Hanna is able to deal with the therapist's laughter/snort in the session 8. The therapist's laughter wasn't just a simple laughter (see Kivikkokangas \& Leiman, 2019), the analysis allows us to see how the laughter referred for Hanna to her father's

${ }^{12}$ In our view, this is the same question as is raised with respect to the various 'meaningful moments 
mockery and scorn (session 25), the previous therapist's laughter at Hanna and her shame about it (Vignette 6), her mothers' mockery and scorn (Vignette 10) and her experiences of being put down as unworthy to do anything in the workplace.

Hanna was able to take initiative in her own hands in order to deal with the experience rupture instead of being silent and ashamed, or silenced by the shame. The feeling of being laughed at and mocked by a significant other is experientially felt, which is something Hanna broaches in a straightforward manner 'You laughed'. The change is significant from Hanna's typical way of coping in the beginning of the therapy by 'being silent and ashamed' (Vignette 2) or silenced by shame (Vignette 2, 16), wanting to say out loud but not being able to 'say anything' than 'everything is good'. The laughter was for Hanna a dangerous referent that threatened to move her to a relational position of being again humiliated and ashamed in front of another. It posed a risk to her trust in and reliance on the therapist, who wouldn't laugh or mock but was interested. This trust had in enabled for her to enter into the therapeutic process. The raised the possibility of shame within the therapeutic relationship, repeating her problematic relation toward the referential object posited in our formulation. Taking this new kind of initiative into one's own hands is not so forthright, it's followed by a step back by not taking seriously the decisiveness of her previous action. The data doesn't show, but it might be argued if in this kind of short-term therapy setting it was crucial for Hanna to keep the image of the therapist as something certain (as someone who doesn't shame, laugh or mock me).

4) Through these steps Hanna was able to narrate her shame story in a new active way, where she understood being identified with her mother's shame on her father's behavior. In addition, she was able to problematize how her relationship toward her father's behavior could have developed in other ways also and not necessarily just shame. Through being able

models' used to understand powerful moments of psychotherapeutic change (Elliott, 1985; Timulak, 2007; Gonçalves \& Ribeiro, 2012). Wahlström (2018, personal communication) condensed the tension in these models in his father's metaphor about a stone cutter: An old man hits a rock with a hammer. He does this many times and hits the rock from every angle. Then, the last hit cuts the rock. The old man then asked a boy who watched this operation, "which hit cut the rock?" The boy answered: 'The last one'. To this the old man replied, 'No, all the hits cut the rock'. To apply this to Hanna's story: Did the change toward her shameful experience happen in those moments in sessions $7-9$ when she expressed this or was it just that at that moment the 'rock shattered'. The problem here is that our position as a third-party researcher robs us of a position where we could solve the old man's riddle.

112 
to 'own her own shame story', which was actually more her mothers', Hanna gained a new type of self-agency toward her life. At the end of the therapy the talk about shame gradually ceased and the focus shifted toward life, about what kind of forms this new kind of activeness takes, and the experiences and emotions different things evoke in her. She was more visible toward herself, others and the world - this was no longer just a threat and horror, but also a joy of being seen and found.

\section{Limitations and Future Directions}

In this study the focus was on Hanna's utterances and how her relationship toward her shame evoking referents changes and develops. This poses at least two central limitations, while also showing aim for future research directions in single case studies. Firstly, by taking Hanna's utterances as the focus of study enables us to take her words and viewpoint as the starting point for analyses. In other words, what Hanna describes her problematic shame experience as is what we follow in our research. On the other hand, this research strategy leaves out of focus how and through what kind of actions of the therapist or interaction this change toward shame was enabled and facilitated. Whereas this study shows that change toward a shame evoking referent did happen during these sessions, a path for further studies could be to use this as a starting point to focus more on 'curative elements', through what kind of interactional processes this observed change was facilitated and enabled. Secondly, APES and DSA are both qualitative methods of single case studies. The aim is not to collect more single case studies that would enable us to see 'whether the pattern obtained here is a typical one or specific to this case' (Goncalves et al., 2013). The subject can't be abstracted from the equation. The aim in this type of research is not to list the semantic positions typical in shame experiences and how these are changed through some generalizable pattern (see Kivikkokangas \& Leiman, 2019).

On the contrary, Hanna's story shows how and through what way her shame had evolved as her shame (and how she tried to cope with it). This can't be abstracted from the idiosyncratic developmental history of the subject (we can't leave the subject out of the equation). Despite the hiding nature of shame, this research shows how and through what way something as difficult to study as shame is, can enter into the sphere of empirical study. Using DSA 
and APES integratively seems a promising microanalytical way to show and track the developmental process and change of manifestations of shame in psychotherapy. Although these findings on the development and change of shame from Hanna's single case study can't be generalized, they can be used in theory building way about the subject of study, namely the manifestation and development of shame through therapeutic process (see Tikkanen, 2015). By taking Hanna's utterance as the starting point for empirical study, she was also returned as the subject of her problematic shame experience at the level of the research.

\section{REFERENCES}

CARO GABALDA, I., \& STILES, W. B. (2013). Irregular assimilation progress: Setbacks in the context of Linguistic Therapy of Evaluation. Psychotherapy Research, 23:35-53.

FREUD, S. (1912). Recommendations to physicians practicing psychoanalysis. SE XII. Hogarth Press, London, pp. 109 - 120.

GONÇALVES, M., CARO GABALDA, I., RIBEIRO, A., PINHEIRO, P., BORGES, R., SOUSA, I. \& STILES, W. (2013). How collaboration in therapy becomes therapeutic: The therapeutic collaboration coding system, Psychother Res, 24:442-455.

HARTIKAINEN, K. (2013). Changes in interaction - a case study [Vuorovaikutuksen muutokset yksilöpsykoterapia prosessissa]. Licenciate thesis. Jyväskylän yliopisto, psykologian laitos.

IKONEN, P., and RECKHARDT, E. (1994). Thanatos, häpeä ja muita tutkielmia [Thanatos, shame and other psychoanalytic studies]. Helsinki: Nuorisopsykoterapiasäätiö.

KETO, R. (2010). Emotion regulation in the psychotherapy of a traumatized woman. [Tunteiden käsittely traumatisoituneen naisen psykoterapiassa]. Licenciate thesis. University of Jyväskylä.

KIVIKKOKANGAS, S. and LEIMAN, M. (2019). Dialogical sequence analysis as a method in theory based single-case studies in psychoanalysis. Scand psychoanal rev, 2:110-118. 
KIVIKKOKANGAS, S., ENCKELL, H. \& LEIMAN, M. (submitted) Self-observation as a precondition for the development of self-analytic capacity.

LEIMAN, M. (1992). The concept of sign in the work of Vygotsky, Winnicott and Bakhtin: further integration of object relations theory and activity theory. Br J Med Psychol, 65 (3):209-221.

LEIMAN, M. (2006). What does the first exchange tell? Dialogical sequence analysis and assimilation in very brief therapy. Psychother Res, 16(4):408-421.

LEIMAN, M. (2012). Dialogical Sequence Analysis as a method to study psychotherapeutic discourse. IJDS, 6(1):123-147.

LEWIS, H.B. (1971). Shame and guilt in neurosis. International Universities, New York.

SIEGEL, D. (2015). The Developing mind. Guilford Press, New York.

STILES, W. B., and ANGUS, L. (2001). Qualitative research on clients' assimilation of problematic experiences in psychotherapy. In J. Frommer \& D. L. Rennie (Eds), Qualitative psychotherapy research: Methods and methodology (pp. 112-127). Lengerich: Pabst Science Publishers. Also published in Psychol Beitr, 43:570-585.

STILES, W. B., ELLIOTT, R., LLEWELYN, S. P., FIRTH-COZENS, J. A., MARGISON, F. R., SHAPIRO, D. A., \& HARDY, G. (1990). Assimilation of problematic experiences by clients in psychotherapy. Psychotherapy, 27(3):411-430.

STILES, W. B., MORRISON, L. A., HAW, S. K., HARPER, H., SHAPIRO, D. A., \& FIRTH-COZENS, J. A. (1991). Longitudinal study of assimilation in exploratory psychotherapy. Psychotherapy, 28(2):195-206.

STILES, W.B. (1999). Signs and voices in Psychotherapy. Psychother res, 9(1):1-21.

STILES, W. B., CARO GABALDA, I., \& RIBEIRO, E. (2016). Exceeding the therapeutic zone of proximal development as a clinical error. Psychother, 53:268-272. 
TIKKANEN, S. (2015). Development of an empathic stance - dialogical sequence analysis (DSA) of a single case during clinical neurological assessment procedure. Publications of the University of Eastern Finland Dissertations in Education, Humanities, and Theology No 68.

TÄHKÄ, R. (2010). Illusion and reality in the psychoanalytic relationship. Scand Psychoanal Rev, 23(1):65-88.

VYGOTSKY, L.S. (1978). Mind in Society. The Development of Higher Psychological Processes. Harvard University Press, Cambridge, MA.

WURMSER, L. (1981). The mask of shame. Johns Hopkins University Press, Baltimore. 